\author{
SANDIA REPORT \\ SAND2010-6473 \\ Unlimited Release \\ Printed September 2010
}

\title{
Biomolecular Transport and Separation in Nanotubular Networks
}

Darryl Y. Sasaki, Carl C. Hayden, Jeanne C. Stachowiak, Steven Branda, George D. Bachand, Robert Meagher, Mark Stevens, David Robinson, Elisa Abate, Amanda Carroll-Portillo, Haiqing Liu, Frank Zendejas, Anupama Sinha, Julia Wang

Prepared by

Sandia National Laboratories

Albuquerque, New Mexico 87185 and Livermore, California 94550

Sandia National Laboratories is a multi-program laboratory managed and operated by Sandia Corporation, a wholly owned subsidiary of Lockheed Martin Corporation, for the U.S. Department of Energy's National Nuclear Security Administration under contract DE-AC04-94AL85000.

Approved for public release; further dissemination unlimited.

\section{Sandia National laboratories}


Issued by Sandia National Laboratories, operated for the United States Department of Energy by Sandia Corporation.

NOTICE: This report was prepared as an account of work sponsored by an agency of the United States Government. Neither the United States Government, nor any agency thereof, nor any of their employees, nor any of their contractors, subcontractors, or their employees, make any warranty, express or implied, or assume any legal liability or responsibility for the accuracy, completeness, or usefulness of any information, apparatus, product, or process disclosed, or represent that its use would not infringe privately owned rights. Reference herein to any specific commercial product, process, or service by trade name, trademark, manufacturer, or otherwise, does not necessarily constitute or imply its endorsement, recommendation, or favoring by the United States Government, any agency thereof, or any of their contractors or subcontractors. The views and opinions expressed herein do not necessarily state or reflect those of the United States Government, any agency thereof, or any of their contractors.

Printed in the United States of America. This report has been reproduced directly from the best available copy.

Available to DOE and DOE contractors from

U.S. Department of Energy

Office of Scientific and Technical Information

P.O. Box 62

Oak Ridge, TN 37831

Telephone: $\quad$ (865) 576-8401

Facsimile: $\quad$ (865) 576-5728

E-Mail: reports@adonis.osti.gov

Online ordering: http://www.osti.gov/bridge

Available to the public from

U.S. Department of Commerce

National Technical Information Service

5285 Port Royal Rd.

Springfield, VA 22161

Telephone: $\quad$ (800) 553-6847

Facsimile: (703) 605-6900

E-Mail: $\quad$ orders@ntis.fedworld.gov

Online order: $\quad$ http://www.ntis.gov/help/ordermethods.asp?loc=7-4-0\#online

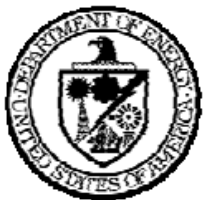


SAND2010-6473

Unlimited Release

Printed September 2010

\title{
Biomolecular Transport and Separation in Nanotubular Networks
}

\author{
Darryl Y. Sasaki ${ }^{\mathrm{a}}$, Carl C. Hayden ${ }^{\mathrm{b}}$, Jeanne C. Stachowiak ${ }^{\mathrm{a}}$, Steven Branda ${ }^{\mathrm{a}}$, George D. \\ Bachand $^{\mathrm{c}}$, Robert Meagher ${ }^{\mathrm{a}}$, Mark Stevens ${ }^{\mathrm{d}}$, David Robinson ${ }^{\mathrm{e}}$, Elisa Abate ${ }^{\mathrm{a}}$, Amanda \\ Carroll-Portillo ${ }^{a}$, Haiqing Liu, Frank Zendejas ${ }^{a}$, Anupama Sinha ${ }^{f}$, Julia Wang ${ }^{b}$ \\ Biotechnology and Bioengineering Dept. ${ }^{\mathrm{a}}$, Combustion Chemistry Dept. ${ }^{\mathrm{b}}$, CINT Science Dept. ${ }^{\mathrm{c}}$, \\ Computational Materials Science and Engineering Dept. ${ }^{\mathrm{d}}$, Energy Nanomaterials Dept. \\ Systems Biology Dept. ${ }^{\mathrm{f}}$ \\ Sandia National Laboratories \\ P.O. Box 969, Livermore, CA 94551 \\ $\&$ \\ P.O. Box 5800, Albuquerque, New Mexico 87185
}

\begin{abstract}
Cell membranes are dynamic substrates that achieve a diverse array of functions through multi-scale reconfigurations. We explore the morphological changes that occur upon protein interaction to model membrane systems that induce deformation of their planar structure to yield nanotube assemblies. In the two examples shown in this report we will describe the use of membrane adhesion and particle trajectory to form lipid nanotubes via mechanical stretching, and protein adsorption onto domains and the induction of membrane curvature through steric pressure. Through this work the relationship between membrane bending rigidity, protein affinity, and line tension of phase separated structures were examined and their relationship in biological membranes explored.
\end{abstract}




\section{ACKNOWLEDGMENTS}

THIS WORK WAS SUPPORTED BY THE LABORATORY DIRECTED RESEARCH AND DEVELOPMENT PROGRAM AT SANDIA NATIONAL LABORATORIES. SANDIA IS A MULTIPROGRAM LABORATORY OPERATED BY SANDIA CORPORATION, A LOCKHEED MARTIN COMPANY, FOR THE UNITED STATES DEPARTMENT OF ENERGY UNDER CONTRACT DE-AC04-94AL85000. 


\section{CONTENTS}

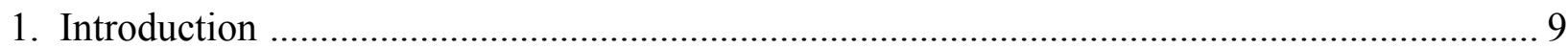

2. Lipid Nanotube Formation from Streptavidin-Membrane Binding..................................... 11

2.1 Introduction 11

2.2 Results and Discussion 12

2.3 Conclusions 16

3. Steric Confinement of Proteins on Lipid Membranes Can Drive Curvature $\begin{array}{ll}\text { and Tubulation } & 19\end{array}$

3.1 Introduction 19

$\begin{array}{ll}3.2 \text { Results } & 20\end{array}$

$\begin{array}{ll}3.3 \text { Discussion } & 26\end{array}$

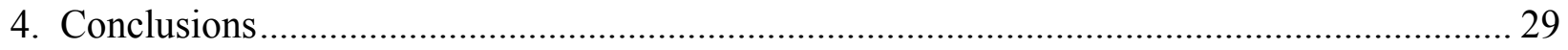

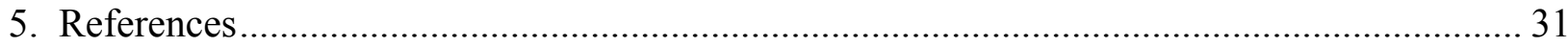

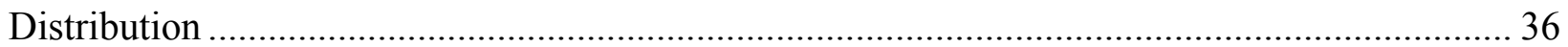

\section{FIGURES}

Figure 1. Nanotubes between adrenal cells $\quad 9$

Figure 2. Schematic of vesicle adhesion induced nanotubes 12

Figure 3. Fluorescence images of vesicles aggregating and tubules 12

Figure 4. Composite image of long lipid nanotube 13

Figure 5. Transport and separation of entrained blebs in lipid nanotubes 14

Figure 6. Confocal microscope images of streptavidin-coated lipid nanotubes 15

Figure 7. Fluorescence images of giant vesicles binding his-tagged GFP 21

Figure 8. Nanotube formation in DSIDA/POPC and DPhPC bilayers 22

Figure 9. Relationship between lipid tubule formation and protein molecular weight 24 
Figure 10. Relationship between lipid tubule length and vesicle size

Figure 11. Schematic of protein crowding and membrane tubulation

\section{TABLES}

Table 1. Phase transition temperatures and bending rigidity values 
NOMENCLATURE

POPC 1-palmitoyl-2-oleoyl-sn-glycero-3-phosphocholine

MOPS morpholino

DOPE dioleoylphosphatidylethanolamine

SOPC 1-stearoyl-2-oleoyl-sn-glycero-3-phosphocholine

DMPC dimyristoylphosphatidylcholine

DPPC dipalmitoylphosphatidylcholine

DSPC distearoylphosphatidylcholine

DLPC dilauroylphosphatidylcholine

eggPC egg phosphatidylcholine

DOPC dioleoylphosphatidylcholine

GUV giant unilamellar vesicle

DSIDA 1,2-distearyl-rac-glycero-3-triethyleneglycyl iminodiacetic acid

DOIDA 1,2-dioleyl-rac-glycero-3-triethyleneglycyl iminodiacetic acid

DPhPC diphytanoylphosphatidylcholine

FCS fluorescence correlation spectroscopy

soyPE soy phosphatidylethanolamine

GFP green fluorescence protein 


\section{INTRODUCTION}

A new pathway in cellular communication that uses lipid nanotubes to transfer biomolecules and organelles between cells has been discovered in macrophages, lymphocytes, and neural cells These recent findings are completely orthogonal to our current understanding of communication between non-adjoined cells, which is thought to proceed largely through chemical signaling. Furthermore, in macrophages nanotubes have been observed to trap and shuttle bacteria for ingestion, while retrovirus infected cells have been observed to generate nanotube connections that enable efficient cell-to-cell virus transmission. Despite the critical role of lipid nanotubes in these processes, little is known about how the structures form, exactly what is being transported, or why these physical intercellular connections are required.

We proposed to study live cells and cell models systems to characterize and develop lipid nanotube constructs that would couple into optical and electronic probes to investigate: 1) the formation of lipid nanotubes, 2) chemical/physical/ biological phenomena that dictate selectivity of transported biomaterial, 3) the origin of forces used to shuttle biomaterials across the nanotube, and 4) the biological significance of the nanotubule connections. Sandia is

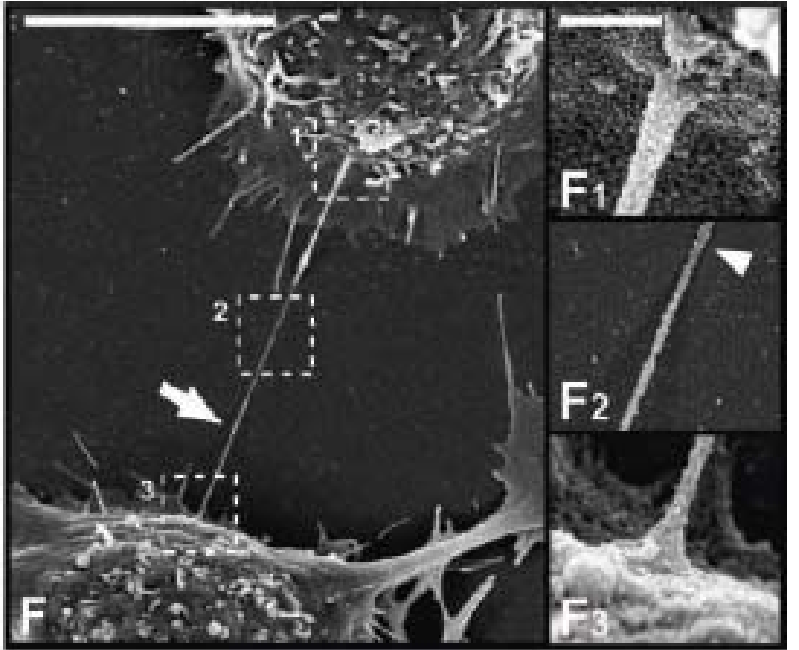

Figure 1. Adrenal cells interacting through lipid nanotubes (from Science 2004, 303, 1007). Scale bars: $\mathrm{F}, 10 \mu \mathrm{m} ; \mathrm{F}_{1}$ to $\mathrm{F}_{3}, 200 \mathrm{~nm}$. particularly suited to address this important biological problem through its expertise in lipid membrane assemblies, theory of membrane structure and dynamics, unique 3D imaging methods, and transport via microelectrophoresis and motor proteins. In this report we describe two methods for creating lipid nanotubules in model systems and discuss their implication for the formation of cellular nanotubes. 


\section{LIPID NANOTUBE FORMATION FROM STREPTAVIDIN-MEMBRANE BINDING}

\subsection{Introduction}

Lipid nanotubes are unique structures that have been observed both between vesicles and, more recently, as connectors between living cells. In cells, nanotubes have typically been observed as membrane extensions from regions facilitating molecular transport or energy conversion, such as the endoplasmic reticulum ${ }^{1}$ and the thylakoid membranes in chloroplasts. ${ }^{2}$ Recently, lipid nanotubes have even been observed serving as cytoplasmic bridges between live cells. $^{3}$ In these instances, tubule diameters of fifty to a few hundred nanometers have been reported with lengths as long as tens of microns. Directed transport of ions, proteins, and even organelles has been monitored in a diverse range of cells, including lymphocytes, ${ }^{4}$ macrophages, ${ }^{5}$ adrenal cells, ${ }^{3}$ and cardiomyocytes, ${ }^{6}$ suggesting the discovery of a new and important form of cellular communication. Several different routes are employed to generate cellular membrane nanotubular structures, such as the polymerization of actin cytoskeletal microfilaments to create membrane filopodia, ${ }^{7}$ the action of cell separation following immunological synapse formation, ${ }^{4}$ motor protein activity against the endoplasmic reticulum, ${ }^{8}$ and through the interaction of BAR domain proteins. ${ }^{9}$ Understanding the physical behavior of lipid membranes and the interfacial interactions that influence membrane curvature and/or viscoelastic behavior would provide fundamental insight into how these structures form and function to modulate cell activity.

Although lipid packing parameters may play a role in nanotube formation, ${ }^{10,11}$ in cell biology the process is dynamic and localized, which suggests that either an interfacial interaction actuates the event or mechanical activity promotes membrane deformation. ${ }^{12}$ Protein-membrane interactions can induce membrane nanotube formation through the protein's structure, such as with the banana shape of amphiphysin, ${ }^{13}$ or through protein assemblies with dynamin ${ }^{14}$ and endophilin, ${ }^{15}$ or even by simply altering the surface charge of the membrane. ${ }^{16}$ Protein binding can also produce changes in the membrane's curvature through anchor insertion and facilitate asymmetry in the membrane structure. ${ }^{17}$ Many examples of induced membrane curvature from proteins are known to play a role in endo-/exocytosis and tubulation, yet surprisingly little is known about the general effect of protein or ligand binding on the structure and physical behavior of lipid membranes. Here, we describe the spontaneous formation of lipid nanotubes from giant lipid vesicles mediated by the strong and specific binding of streptavidin. Several studies suggest protein-membrane interactions can modulate membrane curvature and tension and the results presented here also indicate that the membrane's own bending energy plays a determining role. In Figure 2, we show the proposed method of nanotube formation from streptavidin/biotin-induced interaction to bind and stretch giant vesicles translating in solution. 


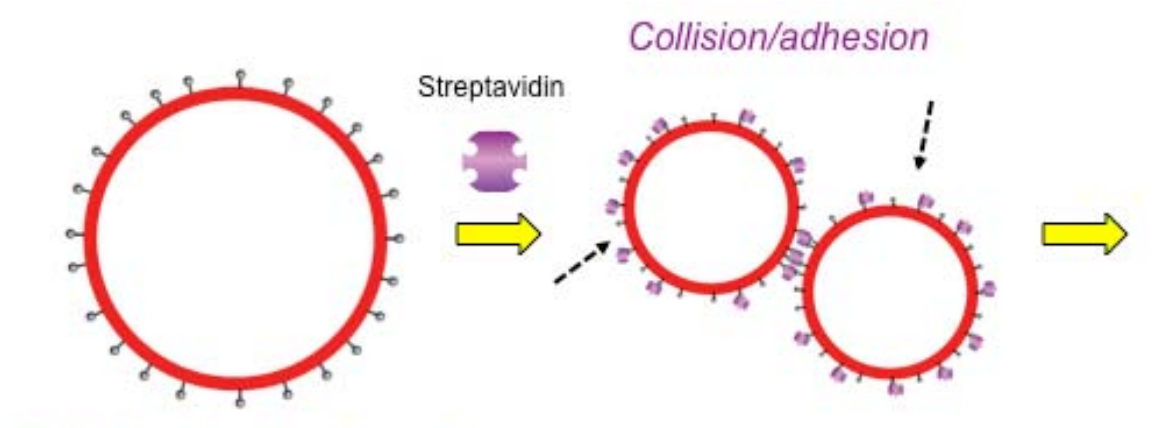

Biotin-functionalized vesicle

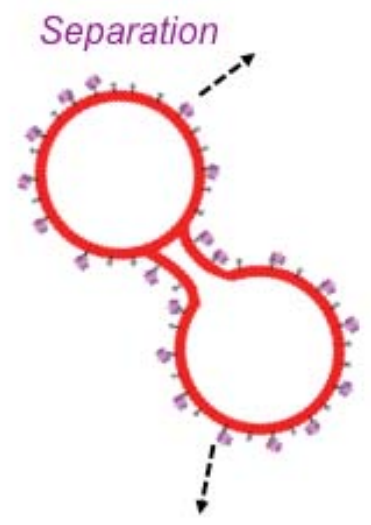

Figure 2. Schematic of the adhesion and tubule formation of biotinylated vesicles through binding interactions with streptavidin.

\subsection{Results and Discussion}

Tubular membrane structures spontaneously formed from giant vesicles composed of 1-palmitoyl2-oleyl-sn-glycero-3-phosphocholine (POPC) with 5 mole \% 1,2-dioleoyl-sn-glycero-3-

phosphoethanolamine-N-biotin (DOPE-biotin) (dia. 1 $-15 \mu \mathrm{m})$ when exposed to streptavidin at a concentration of $0.6 \mu \mathrm{M}(5: 1$ DOPE-biotin to streptavidin) in MOPS buffer (pH 7.4). Following an incubation period of ca. 1 hour at room temperature some of the vesicles aggregated while others fused into larger vesicles (Figure 3A) or produced lipid nanotubes (Figure 3B). By fluorescence and confocal microscopy nanotubes widths were measured from a few microns to below the diffraction limit and lengths of up to hundreds of microns. An example of a 300 $\mu \mathrm{m}$ long nanotube is shown in Figure 4. The nanotubes were typically found as relatively rigid structures held between vesicles attached to the glass surfaces. In other cases one vesicle was anchored to the surface and the other was dangling free in solution. Entangled networks of nanotubes could be found, as well as ones with vesicles attached upon and within the tubes.

Streptavidin-membrane interaction has been known to facilitate the aggregation of vesicles for use as potential drug delivery vehicles ${ }^{18}$ and has been observed to cause giant
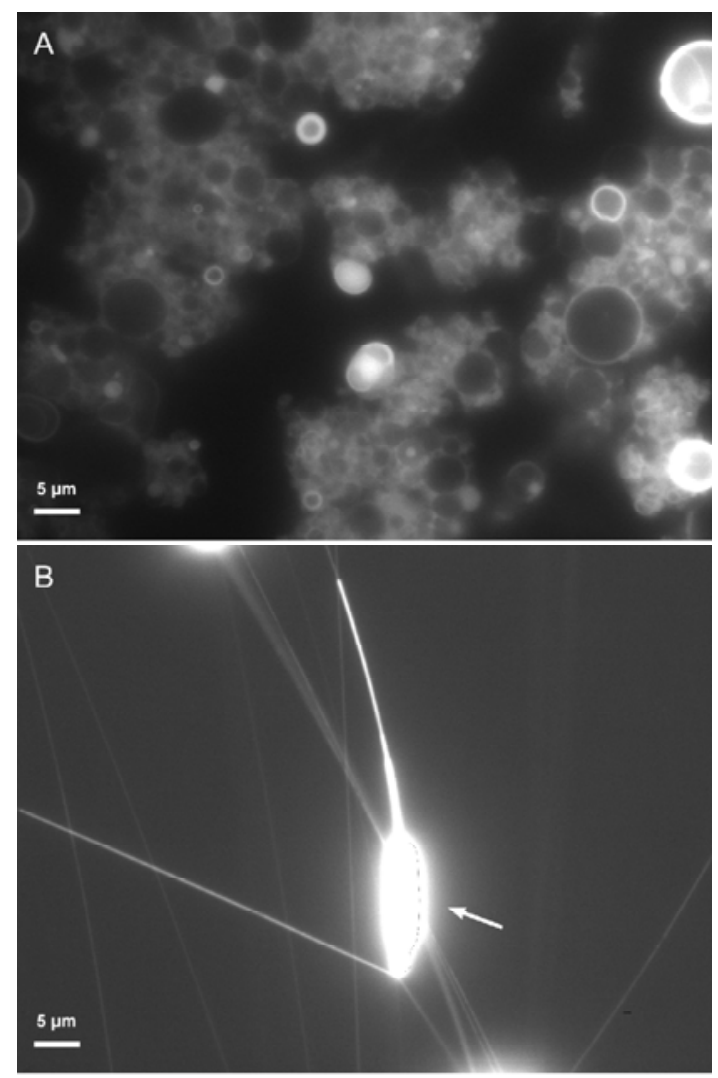

Figure 3. Fluorescence microscope images of $0.3 \% \mathrm{DiA} / 5 \%$ DOPE-biotin/POPC giant vesicles following exposure to Alexa 635labeled streptavidin showing A) aggregated vesicles and $\mathrm{B}$ ) nanotubes. 
vesicles to deform to oblate structures from protein crystallization, ${ }^{19}$ however, nanotube formation has not been previously reported. The process is specific to the streptavidin-biotin recognition as vesicles lacking DOPEbiotin were unaffected by streptavidin presence. Additionally, only with freshly prepared streptavidin were high densities of nanotubes (several dozen per $\mathrm{cm}^{2}$ ) observed. Older solutions of streptavidin exhibited a diminished ability to stimulate nanotube formation suggesting loss of protein activity. On the short time scale $(<30 \mathrm{~min})$ streptavidin induced the tubulation of giant vesicles into worm-like structures in solution (Supporting Information). As time progressed these structures gave way to the longer lived nanotubes spanning between surface adhered vesicles. These tubes were typically stable for at least a day.

As the vesicle-tubule networks initially form, substantial dynamic restructuring typically followed. During this process the assemblies exhibited marked viscoelastic behavior that facilitated the transport and separation of liquid blebs within the nanotubes.

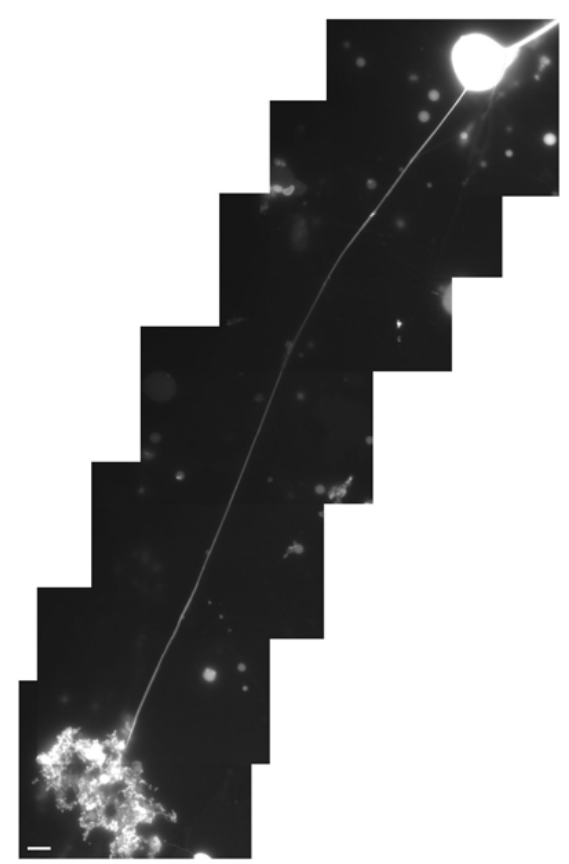

Figure 5 shows one example in which two lipid nanotubes become entangled at a catch point and demonstrates the elastic behavior and fluidic transport of the nanotubes. One of the tubes (tube 1) ran relatively straight from the bottom of the image to the left side. The other tube (tube 2) appeared from the bottom of the right side, made a sharp bend around tube 1 then exited through the top. Blebs of liquid of different sizes, which may actually be vesicles that cannot be clearly resolved by the microscope, appeared to be entrained within the lower half of tube 2. A small bleb within tube 2 was trapped at a "catch point" where the two nanotubes cross (Figure 5A, white arrow). A small surge of turbulent fluid in the sample towards the upper left corner of the image causes tube 2 to be drawn in that direction. The pulling action occurred with sufficient force to transport the small bleb past the catch point and further along as the tube was drawn by the flow shear (white arrow in Figures 5B, 5C, and 5D). Simultaneously, larger blebs further down on tube 2 were drawn toward and became trapped against the catch point (grey arrows in Figures 5B and 5C). The fluidity of the lipid nanotube became apparent as the distance between blebs rapidly changed through mechanical force of the fluid flow and by the physical traps set by the entangled nanotubes. Similar bleb transport has been observed with nanotubes formed by electroformation. ${ }^{20}$

Streptavidin has been observed to induce a change in membrane curvature through protein crystallization on the outside surface of giant vesicles. The Gast lab has shown that streptavidin crystallized against biotionylated giant vesicles of 1-stearoyl-2-oleoyl-sn-glycero-3phosphatidylcholine (SOPC) produces vesicle ruffling and oblate structure formation. ${ }^{19,21}$ As solution $\mathrm{pH}$ increased from 4.3 to 6.3 , streptavidin crystals grew as long and thin structures with parallel orientation over the membrane surface inducing elongation of the vesicles. Since the isoelectric point of the protein occurs at $\mathrm{pH} 5-6$, it was argued that increasing $\mathrm{pH}$ resulted in smaller crystals due to electrostatic repulsive forces. At $\mathrm{pH} 7.0$, the protein became 
homogenously distributed over the vesicle surface without any crystallization detectable by fluorescence microscopy.

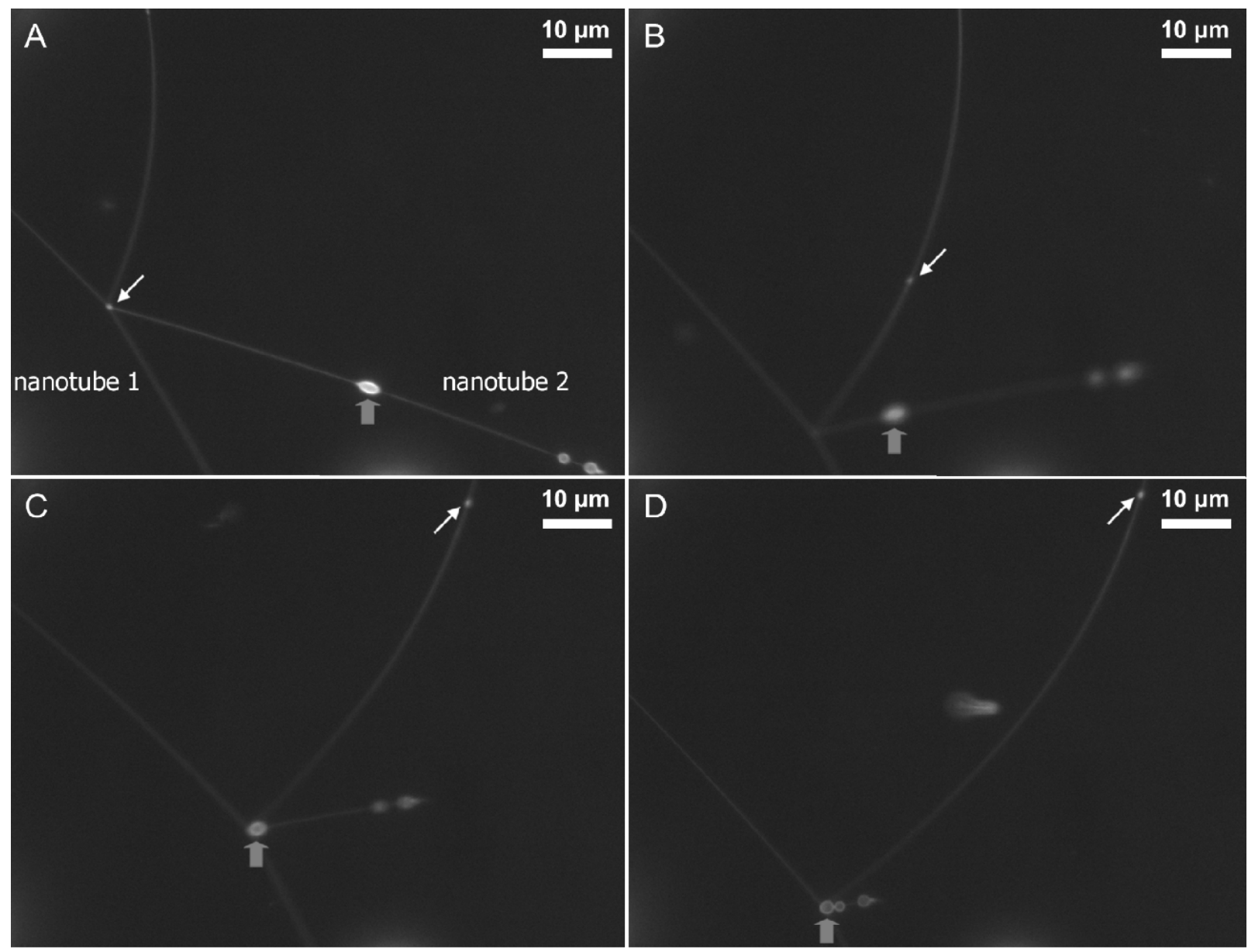

Figure 5. Transport and separation of entrained blebs observed within a nanotube as they were impeded by entanglement with another nanotube. A small bleb (followed by a white arrow) (A) initially caught at the point of entanglement (B) traversed past the physical barrier of the nanotube and continued transport upward via the shear force of the fluid flow moving to the upper left corner of the image. Simultaneously, a larger bleb (grey arrow) (C) transported towards the catch point and became physically trapped. (D) Other large blebs similarly followed towards the catch point and collect.

In other work streptavidin has been shown to form helical arrays against lipid nanotubes composed of glycolipids at $\mathrm{pH} 7.5 .^{22,23}$ This behavior attests to appropriate packing parameters of streptavidin at neutral $\mathrm{pH}$ to accommodate nanotubular architectures through tightly bound protein interactions on the membrane surface. The area occupied by streptavidin $(55 \AA \mathrm{x} 45 \AA \mathrm{x}$ $50 \AA$ ) covers $\sim 50$ lipid molecules $\left(\sim 45 \AA^{2} /\right.$ lipid), or roughly 100 lipids per streptavidin bound to the outer membrane leaflet of the vesicles. Considering our biotin loading of 5 mole $\%$ in the vesicles tubulation could thus be argued as a means by which the membrane has reorganized to accomodate high densities of biotin-streptavidin coupling. We have also examined vesicles loaded with 1 mole \% biotin and noted reduced quantities of nanotubes, further supporting a mechanism involving protein crowding on the membrane surface. Confocal imaging using fluorescent-labeled streptavidin (tetramethylrhodamine) with non-labeled giant vesicles 
confirmed that the protein was homogeneously bound along the length of the nanotubes (Figure 6). Another interesting observation was the formation of worm-like tubules in solution shortly after streptavidin addition that further suggests a protein-induced increase in membrane curvature. Because protein-membrane reorganizational processes proceed over periods of hours following initial protein complexation (as similarly observed for lectin ${ }^{24}$ and myoglobin ${ }^{25}$ ), it is not surprising that nanotube formation experiences long transformation times before yielding equilibrated structures.

Nanotube formation

may also occur via the mechanical stretching of membranes as two vesicles on different trajectories make contact, adhere, and then pull apart in the fluidic environment. Similar to cell separation following immunological synapse formation, ${ }^{4}$ vesicles intimately bound through adhesion from biotin-streptavidin interaction may use their inertial moments as a mechanical force to stretch and extend the membrane to form nanotubes. This hypothesis was partially supported by direct microscopic observations of such events as nanotubes extended from surface adhered vesicles. By flowing a solution

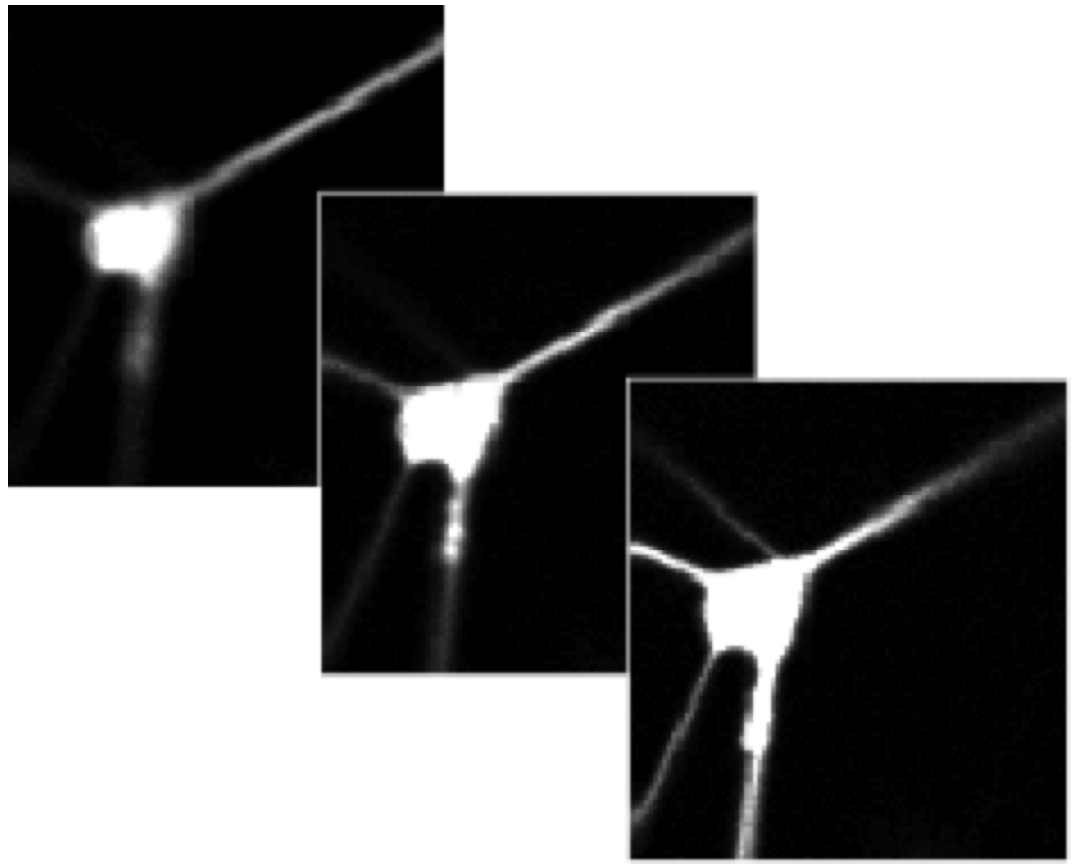

Figure 6. A sequence of confocal images with the z-axis scanned in 1 $\mu \mathrm{m}$ depth per image (image area $-20 \mu \mathrm{m} \times 20 \mu \mathrm{m}$ ). Lipid membranes are unlabeled so the fluorescence signal obtained was from tetramethylrhodamine-labeled streptavidin. The stack of images exposes the 3D architecture of the nanotube networks. containing giant vesicles with streptavidin through a microfluidic cell, nanotubes of several millimeters in length could also be produced as small vesicles were drawn downstream from larger vesicles attached to the channel surface (data not shown). The adhesive force is aptly supplied by biotin-streptavidin interactions on the vesicle surfaces, but the taut nature of the nanotubes and the physical robustness displayed in Figure 5 suggest an enhancement in membrane tension. This observation is consistent with previous work by Hirn and coworkers ${ }^{26}$ where three fold increases in membrane tension of biotinylated phosphocholine bilayers were found upon the binding of streptavidin.

In an effort to provide some insight into the role of the membrane's physical properties in protein-induced tubulation we compared a range of PC lipid membranes existing at different phases and bending energies. For giant vesicles composed of dipalmitoylphosphatidylcholine (DPPC), distearoylphosphatidylcholine (DSPC), dimyristoylphosphatidylcholine (DMPC), and egg phosphatidylcholine (egg PC), vesicle aggregation dominated the sample upon streptavidin addition. With vesicles of dilauroylphosphatidylcholine (DLPC), dioleoylphosphatidyl choline (DOPC), and POPC, on the other hand, spontaneous nanotube formation occurred, along with vesicle aggregation. Bilayers existing in the gel phase might be expected to resist deformation to 
highly curved nanotubular structures, whereas those in the fluid phase should accommodate such structural transformations. Such expectations were generally observed as DSPC, DPPC, and DMPC vesicles predominantly aggregated while the fluid phase POPC, DLPC, and DOPC yielded nanotubes. Curiously though, bilayers composed of eggPC, a fluid phase membrane at room temperature $\left(\mathrm{T}_{\mathrm{g}}=-5\right.$ to $\left.-10^{\circ} \mathrm{C}\right)$ did not produce nanotubes, although it has been successfully used to form nanotubular structures via mechanical pulling with micropipets. ${ }^{27}$

Table 1. Phase transition temperatures and bending rigidity values as related to nanotube formation.

\begin{tabular}{|c|c|c|c|c|}
\hline Lipid & $\begin{array}{c}\text { Phase transition } \mathrm{T} \\
\left({ }^{\circ} \mathrm{C}\right)\end{array}$ & $\begin{array}{l}\text { Bending rigidity } \kappa(x \\
\left.10^{-20} \mathrm{~J}\right)\end{array}$ & $\begin{array}{l}\text { Nanotube } \\
\text { formation }\end{array}$ & Ref. \\
\hline DSPC & 55 & $18\left[@ 56.5^{\circ} \mathrm{C}\right]$ & - & 29 \\
\hline DPPC & 41 & $20\left[@ 44^{\circ} \mathrm{C}\right]$ & - & 29 \\
\hline DMPC & 23 & $24\left[@ 28^{\circ} \mathrm{C}\right]$ & - & 29 \\
\hline Egg PC & $-10--5$ & 8 & - & 15 \\
\hline DLPC & -1 & 3.37 & + & 17 \\
\hline POPC & -2 & 3.9 & + & 16 \\
\hline DOPC & -20 & 2.4 & + & 16 \\
\hline
\end{tabular}

Another important membrane property that correlates with nanotube formation is membrane bending rigidity $(\kappa) .{ }^{28}$ A compilation of $\kappa$ values from the literature is shown in Table 1. ${ }^{29,30,31,32}$ (It should be noted that these values tend to be somewhat variable depending on the measuring technique and conditions.) These data provide a minimal basis for rationalizing a correlation of the contribution of membrane bending energy to spontaneous tubulation by protein binding interactions. A threshold membrane bending energy of $8-4 \times 10^{-20} \mathrm{~J}$ (ca. 10kT) was identified as the value up to which tubule formation occurs upon streptavidin binding. Similar threshold values may also exist for nanotube formation in cells, which highlights the importance of membrane composition for proper cellular function. As bending energy attenuates with rising temperature it should be possible to expand the range of lipids and lipid compositions available for nanotube formation in our synthetic systems. Additionally, we note that the giant vesicles used in these studies were not uniformly unilamellar, but also contained multilamellar structures. Future investigations will probe the influence of membrane lamellarity, as well as membrane composition, on curvature and tubulation.

\subsection{Conclusion}

We have shown that strong protein interactions can elicit remarkable transformations in the structural organization of planar lipid membranes to nanotubular architectures. The precise mechanism of nanotube formation remains unclear at this time, however, evidence exists for processes that involve enhanced interfacial adhesion of colliding vesicles as well as steric interactions that promote membrane curvature. The lipid tubules exhibited membrane fluidity that facilitated the transport of entrained liquid blebs or vesicles and physical stability towards 
mechanical stress. Further studies will be continued to elucidate the mechanism of spontaneous nanotube formation and examine the use of these assemblies for transport and separation of nanoassemblies. 


\section{STERIC CONFINEMENT OF PROTEINS ON LIPID MEMBRANES CAN DRIVE CURVATURE AND TUBULATION}

\subsection{Introduction}

Lipid membranes provide a dynamic substrate for biomolecular interactions that underlies environmental response and compartmentalized function in cells. Highly curved membrane structures are critical for a variety of cellular processes including endocytosis, cytoskeletal protrusion, organelle synthesis, and cell division ${ }^{33}$. Curved membrane assemblies such as lipid tubules and buds have also been of interest as controllable nanomaterials such as scaffolds for biological-synthetic hybrid materials ${ }^{34,35}$ and conduits to move species within nano-fluidic networks. ${ }^{36}$ However, a well-controlled method for the self-assembly of complex membrane structures and networks has yet to emerge.

Cells use a variety of mechanisms to induce curvature in their membranes including cytoskeletal pushing and pulling, binding of curved proteins to membranes, scaffolding of the membrane by curved protein lattices, insertion of amphipathic peptide helices into a single leaflet of the membrane, and asymmetric changes in the membrane lipid composition. ${ }^{33,37}$ Cells orchestrate the size, location, number, and lifetime of a variety of diverse membrane protrusions. Greater understanding of how this extraordinary coordination is accomplished is needed not only to understand cellular processes that depend on protrusion but also to identify principles that could be used to assemble programmable soft-material structures and networks.

Some of the most studied membrane protrusions are endocytic structures such as clathrin coated pits and caveolae. The curvature of these structures is thought to arise from proteininduced membrane bending, where concentrated application of steric pressure within structures plays an important role. During clathrin mediated endocytosis it is believed that epsin family proteins insert amphipathic helices in the cytoplasmic membrane leaflet to induce curvature. The structured clathrin coat concentrates epsins leading to membrane budding. ${ }^{38}$ In the formation of caveolae, caveolins are known to oligomerize ${ }^{39}$ and have been hypothesized to deform the bilayer through application of steric pressure. ${ }^{40}$

In addition to protein binding, lipid membrane organization may also play a role in membrane bending during endocytosis. Specific membrane species such as cholesterol and sphingomylin are known to co-localize with or enable highly curved membrane structures including clathrin-coated pits, ${ }^{41}$ caveolae, ${ }^{42}$ and synaptic vesicles ${ }^{43}$ possibly forming domains rich in cholesterol and sphingolipids. A variety of roles for lipid domains relevant to the formation of protrusions have been explored previously. ${ }^{46}$ Examples include concentration of signaling receptors, ${ }^{42}$ sorting of membrane proteins, ${ }^{44,45}$ and modification of bilayer mechanical properties. $^{37,46}$ However, the specific mechanisms by which lipid organization collaborates with protein binding to induce membrane deformation remain unknown.

We explore possible collaboration between proteins and lipid domains in membrane protrusion by constructing a simplified synthetic model system using giant unilamellar vesicles (GUVs). These vesicles each contain a lipid domain that strongly binds poly-histidine-tagged proteins. ${ }^{47}$ Using this approach we have demonstrated that domains are capable of tightly concentrating protein binding interactions. Remarkably, this concentration leads to lateral steric crowding of proteins within the domain that bends the membrane, inducing spontaneous formation of lipid buds and tubules. Tubule formation was found to be dependent upon the 
solubility of lipids with negative spontaneous curvature in the domain and the density of protein attachment. Most domains yield a single tubule, and tubules frequently consume the entire protein-coated domain such that the domain size tightly defines the tubule surface area. Further, tubule length and diameter were found to vary linearly with vesicle diameter. A simple physical analysis shows that this coupling is consistent with a globally limited membrane tension defined by protein-lipid binding energy. While this synthetic model system is highly simplified, it demonstrates that lipid domains and other confining structures such as protein lattices could aid in the formation of protrusions and define protrusion length scales by concentrating the steric interactions between the lipid bilayer and proteins. Further, these findings suggest an approach for polarizing and ordering lipid-based materials by self-assembly.

\subsection{Results}

\subsubsection{Lipid domains can confine protein binding on vesicle surfaces}

To study the effects of confining protein binding to a specific region on a lipid membrane, we formed giant unilamellar vesicles (GUVs) containing insoluble domains that serve as high affinity sites for his-tagged proteins. These vesicles consisted of the lipid DSIDA (distearylglycero triethyleneglycyl iminodiacetic acid) ${ }^{48}$ in a 1:9 molar ratio with matrix lipids (e.g., POPC, DPhPC). DSIDA has a phase transition temperature at $55^{\circ} \mathrm{C}$ that increases to 73 ${ }^{\circ} \mathrm{C}$ upon binding with $\mathrm{Cu}^{2+}$ ion. In the fluid phase matrix lipids it forms insoluble domains on the surfaces of supported lipid bilayers ${ }^{47}$ and GUVs when mixed with fluid phase matrix lipids at room temperature. The fluorescent probe BODIPY partitions preferentially to fluid phase regions of the membrane revealing dark gel-phase domains rich in $\mathrm{Cu}^{2+}$-bound DSIDA. For comparison, we prepared GUVs with the same mole fraction of protein affinity sites uniformly distributed over the entire vesicles surface by mixing the fluid phase metal chelating lipid DOIDA (dioleylglycero triethyleneglycyl iminodiacetic acid) ${ }^{49}$ at a 1:9 molar ratio with matrix lipids.

The $\mathrm{Cu}^{2+}$-IDA complex of the $\mathrm{Cu}^{2+}$-bound DSIDA and DOIDA lipids act as high affinity sites for histidine and, his-tagged proteins. When GUVs containing DOIDA were exposed to his-tagged green fluorescing protein (his-GFP), an evenly distributed coverage of protein on the vesicle surfaces was observed (Fig. 7A). In contrast, when GUVs containing DSIDA were exposed to his-GFP, protein binding only occurred in a well-defined region of the vesicle surface that strongly co-localized with the DSIDA-rich dark domain (Fig. 7B center, right). Therefore, lipid domains composed of $\mathrm{Cu}^{2+}$-bound DSIDA confined and concentrated protein binding interactions with the vesicle surface. 


\subsubsection{Protein binding can deform domains into buds and tubules.}

Concentration of protein binding interactions on domain surfaces led to remarkable changes in their shape. Originally flat domain surfaces were rapidly bent into puckered surfaces (Fig. 7C) and bulges (Fig. 7D) upon protein binding. The most dramatic shape change was the frequent formation of long, thin tubules from domains upon protein binding (Fig. 7E). Membrane deformations and tubule formation were observed within minutes after protein addition.

From confocal fluorescent images of tubules extending from vesicle surfaces (Fig. 7 A,B) we estimate that $80 \%$ of the vesicles forming tubules have a single tubule. Further, many tubules take up the entire domain area (Fig. 7E). These observations suggest that initiation of a tubule by forming an initial high curvature bud presents a higher energetic barrier than extension of an existing bud into a tubule. Membrane shape changes and formation of tubules were not found for DOIDA-containing vesicles, where the protein binding sites were distributed evenly over GUV surfaces, demonstrating that concentration of protein

A
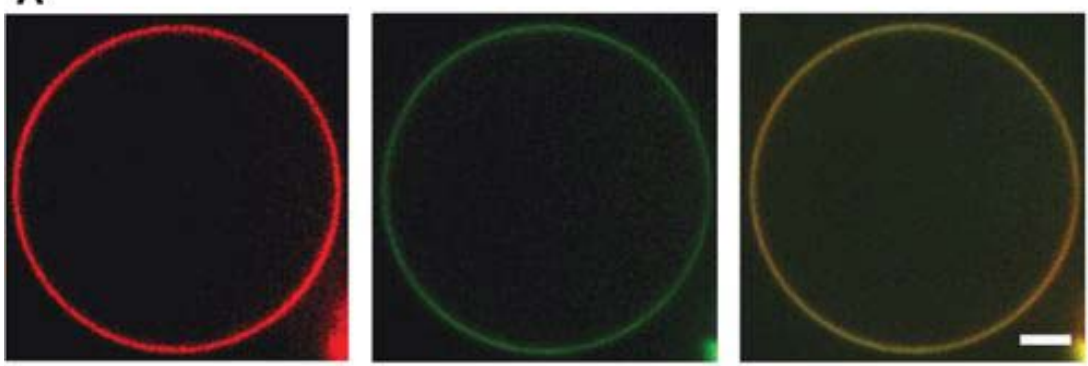

B
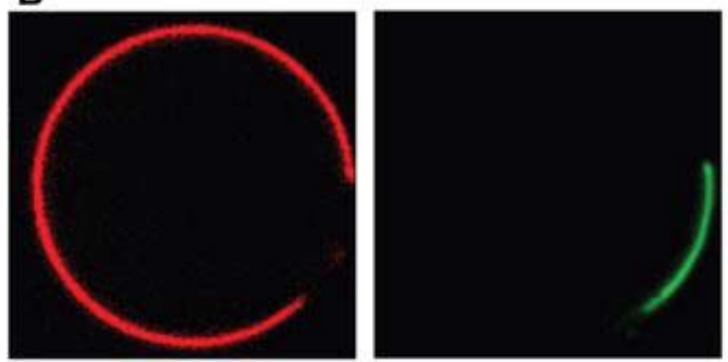

C

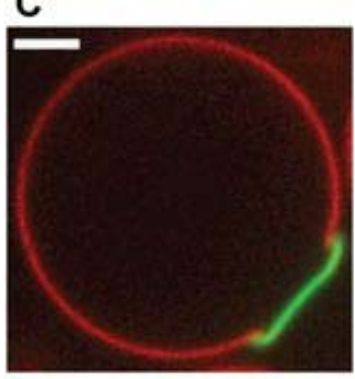

D
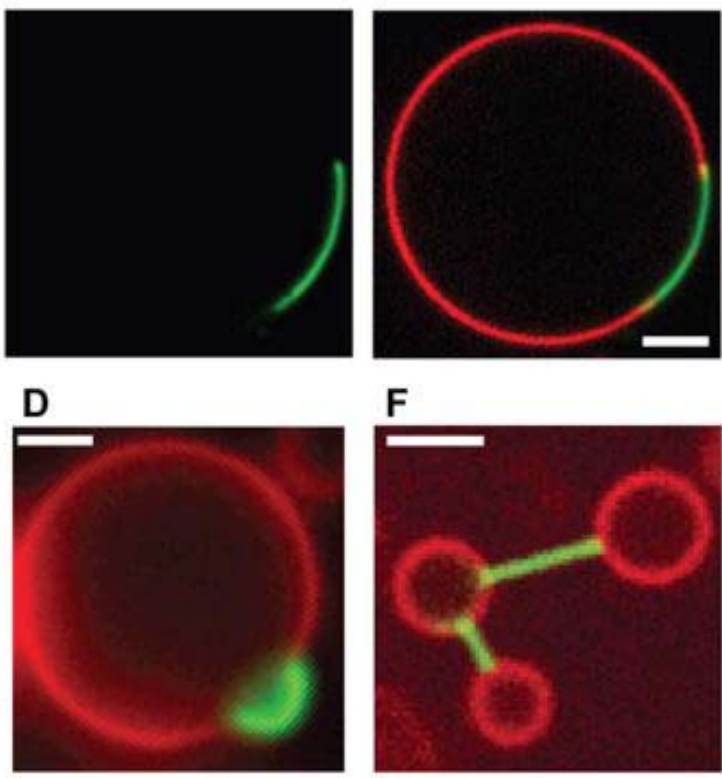

$\mathbf{F}$

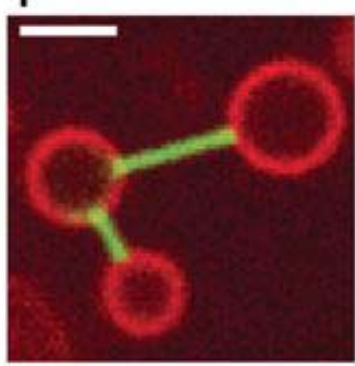

E

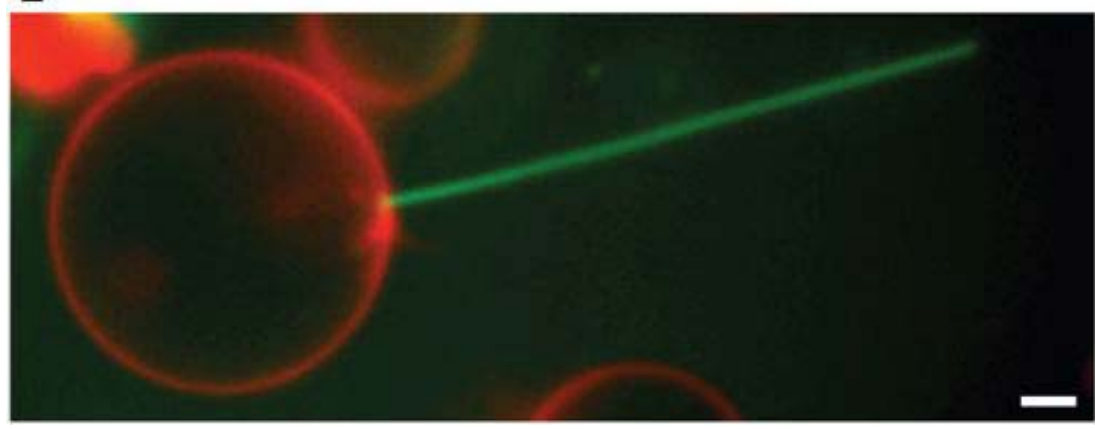

Figure 7. A) GUVs containing $10 \%$ DOIDA have a uniform distribution of the membrane dye and surface protein binding (Left: BODIPY, Center: GFP, Right: merge). (B) GUVs containing 10\% DSIDA form domains that exclude the membrane dye and concentrate protein binding (Left: BODIPY, Center: GFP, Right: merge). (C) Protein binding to the domain frequently leads to domain puckering (merged image), (D) bulging and (E) lipid tubule formation. (F) Tubules protruding from one vesicle encounter other vesicles and form stable connections. (Scale bars $=2 \mu \mathrm{m}$ ).

binding at a well-defined, high affinity region of the vesicle surface is required for shape change. 


\subsubsection{Affect of lipid composition on tubule formation}

We examined the impact of lipid membrane on the deformation of lipid domains by protein binding and found that the frequency of tubule formation varied considerably with the lipid composition (Fig. 8). We initially examined the frequency of tubule formation using two different matrix lipids, POPC and DPhPC. We found that tubules frequently formed $(0.42+/-$ 0.07 tubes/vesicle) using 10\% DSIDA / 90\% DPhPC while they formed much more rarely $(0.02+/-0.01$ tubes/vesicle) using 10\% DSIDA / 90\% POPC, Fig. 8 (A,B,F). Two other fluid phase phosphocholine matrix lipids that were tried, DLPC and DOPC, demonstrated that the tubulation process was not a general phenomenon of a protein-binding, gel phase domain residing within a fluid phase matrix. In considering bending rigidities, POPC $\left(\sim 3.9 \times 10^{-20} \mathrm{~J}\right)^{51}$ and DLPC $\left(\sim 3.4 \times 10^{-20} \mathrm{~J}\right)^{50}$ were comparable and DOPC $\left(\sim 1.9 \times 10^{-20} \mathrm{~J}\right)^{51}$ was only slightly lower, but the POPC-containing membranes produced far more tubes than both. In these experiments the concentration of the membrane dye ranged between $0.03-0.3$ mole $\%$, with no apparent influence on the results.

We further hypothesized that membrane tubulation might be dependent upon the solubility of the DSIDA domains with the matrix lipid. Enhanced solubility could fluidize domains, reducing curvature energy. We performed fluorescence correlation spectroscopy (FCS) measurements on supported lipid bilayers to compare the diffusivity of dye molecules within

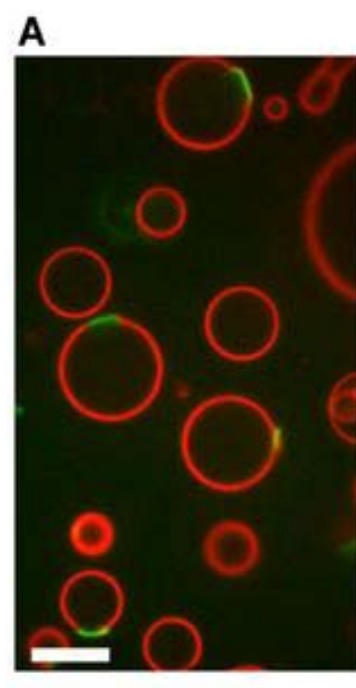

B
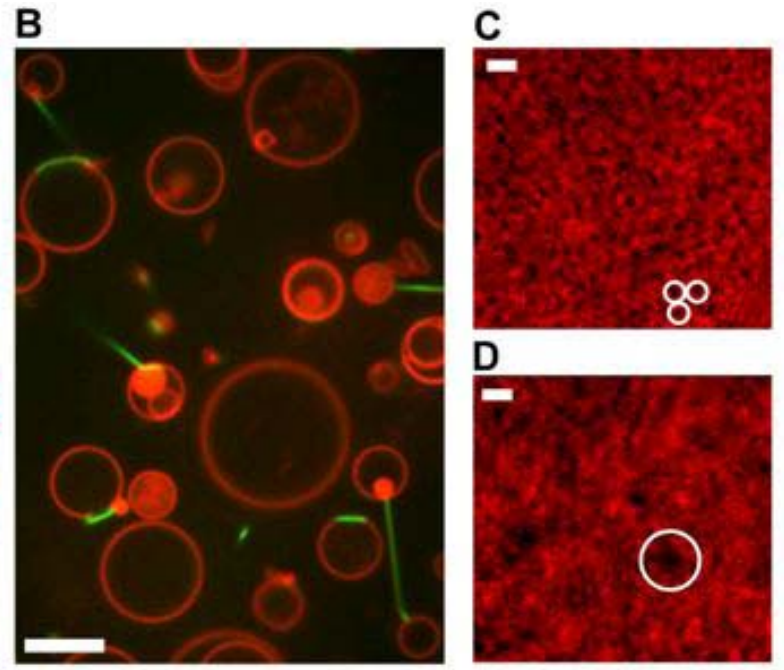

E

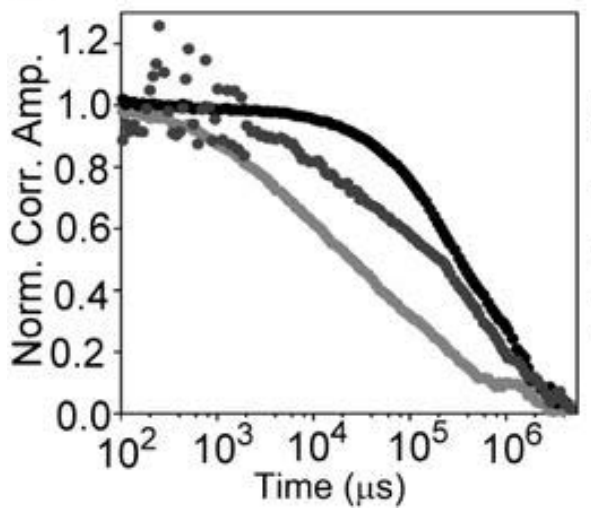

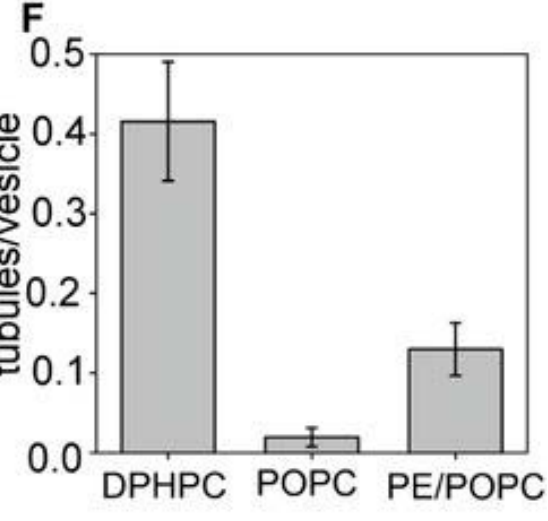

Figure 8. GUVS containing (A) - (10\% DSIDA / 89.7\% POPC / 0.3\% BODIPY ) and (B) - ( 10\% DSIDA / 89.7\% DPhPC / 0.3\% BODIPY ) with $2 \mu \mathrm{M}$ his-GFP. Scale bars for (A, B) are $5 \mu \mathrm{m}$ long. SLBs containing (C) (10\% DSIDA / 89.97\% POPC / 0.03\% BODIPY) and (D) - (10\% DSIDA / $89.7 \% \mathrm{DPhPC} / 0.3 \% \mathrm{BODIPY})$ form insoluble domains. Scale bars of (C, D) are $2 \mu \mathrm{m}$. White circles contain DSIDA-rich insoluble domains. (E) FCS data (normalized correlation amplitude versus time) for BODIPY fluorescence shows that fluorophores outside DSIDA domains in a POPC matrix diffuse at about $0.04 \mu \mathrm{m}^{2} / \mathrm{s}$ (light gray), and fluorophores inside these domains diffuse at about $4.7 \mu \mathrm{m}^{2} / \mathrm{s}$ (black). 
domains to assess local membrane fluidity. Using the $10 \%$ DSIDA/ $90 \%$ DPhPC membrane, we observed the unstable formation and dissolution of $\mathrm{Cu}^{2+}$-DSIDA-rich domains (Fig. 8D) multiple times per minute. FCS measurements showed both fast and slow components with diffusion constants characteristic of fluid and gel phase membranes, respectively, on the time scale of the FCS measurements (Fig. 8E). This behavior contrasts with the stable $\mathrm{Cu}^{2+}$-DSIDA-rich domains formed in the 10\% DSIDA/90\% POPC membrane (Fig. 8C), which gave only a single very slow diffusion component. ${ }^{47}$

Domain fluctuations similar to those we observe in the DSIDA/DPhPC system are also known to occur in ternary lipid mixtures on GUVs just above liquid-liquid miscibility phase transitions temperatures. The transient nature of DSIDA/DPhPC domains as observed as a supported membrane on glass may suggest that the system is near a miscibility phase transition when observed at room temperature. These domains appear highly stable when observed on GUVs (Fig. 7B). However, substrate-membrane interactions have been known to shift phase transition temperatures of SLBs. This suggests that DSIDA/DPHPC mixtures as SLBs may exist near a miscibility phase transition at room temperature. The difference in domain stability between DSIDA/DPHPC and DSIDA/POPC SLBs, then, may simply result from a difference in the phase-stability of the two mixtures, which ultimately impacts the domain composition of GUVs. To evaluate this possibility we investigated the solubility of DSIDA in both DPhPC and POPC at room temperature. We formed GUVs with decreasing DSIDA content from $7.5 \mathrm{~mol} \%$ to $3 \mathrm{~mol} \%$ and measured the size of resulting DSIDA-rich domains. Vesicles of DSIDA/POPC contained domains that decreased in size approximately linearly with decreasing DSIDA content. In contrast, vesicles of DSIDA/DPhPC displayed a sharp decrease in domain size between 7.5 $\mathrm{mol} \%$ and $6 \mathrm{~mol} \%$ and no micron-scale domains below $6 \mathrm{~mol} \%$. These results further add to the supposition that at room temperature, the DSIDA/DPhPC system is nearer to a miscibility phase transition than is the DSIDA/POPC system. DPhPC thus exhibits higher solubility in the DSIDA-rich domains compared to POPC, thereby enhancing the fluidity of the DSIDA-rich domains and reducing the energetic barrier to tubule formation.

Finally, we hypothesized that the DPhPC might aid the formation of tubules because of its negative spontaneous curvature in comparison to other PC lipids tested. ${ }^{52}$ Lipids of high negative spontaneous curvature might assist tubule formation by populating the negative curvature region at the tubule base or the tubule inner membrane leaflet. Lipids of negative spontaneous curvature, such as phosphatidyl ethanolamine (PE) lipids, are known to partition to regions of high curvature in cells, often distributing asymmetrically between lipid leaflets to promote curvature. ${ }^{53} \mathrm{We}$ formed GUVs that contained small amounts $(0.1-1 \%)$ of Soy PE in the DSIDA/POPC bilayers. We had previously observed that SoyPE was highly soluble in domains as evidenced by an increase in size of the domains when larger fractions of SoyPE were included (10-40\% SoyPE). Therefore, we estimate that SoyPE partitions to the domains such that the percentage of SoyPE was likely $1-10 \%$ within them. We found that addition of this small fraction of SoyPE produced about 6-7 times more tubules than POPC alone $(0.13$ tubes/vesicle). Although with SoyPE we were not successful in separating the effects of domain fluidity and negative spontaneous curvature, it does appear that both factors contribute to the reduction of the energetic barrier to tubule formation.

\subsubsection{Affect of protein binding on tubule formation}

In addition to lipid composition, variations in the his-tagged protein composition and

concentration may impact membrane deformation. We varied the concentration of his-GFP in 
solution and found a monotonic increase in the frequency of tubule formation of more than fourfold as protein concentration increased from $20 \mathrm{nM}$ to $2 \mu \mathrm{m}$ (Fig. 9A) $\left(\mathrm{K}_{\mathrm{d}} \sim 2 \mathrm{nM}\right) .{ }^{48}$ Below $20 \mathrm{nM}$, protein bound on the lipid bilayers could not be discerned from background fluorescence. The increase in tubule formation with protein concentrations several orders of magnitude above the dissociation constant suggests that tubule formation relies on a very high fractional occupancy of protein on the domain surface. Additionally, the dissociation constant may increase as protein surface coverage reaches saturation within the domain.
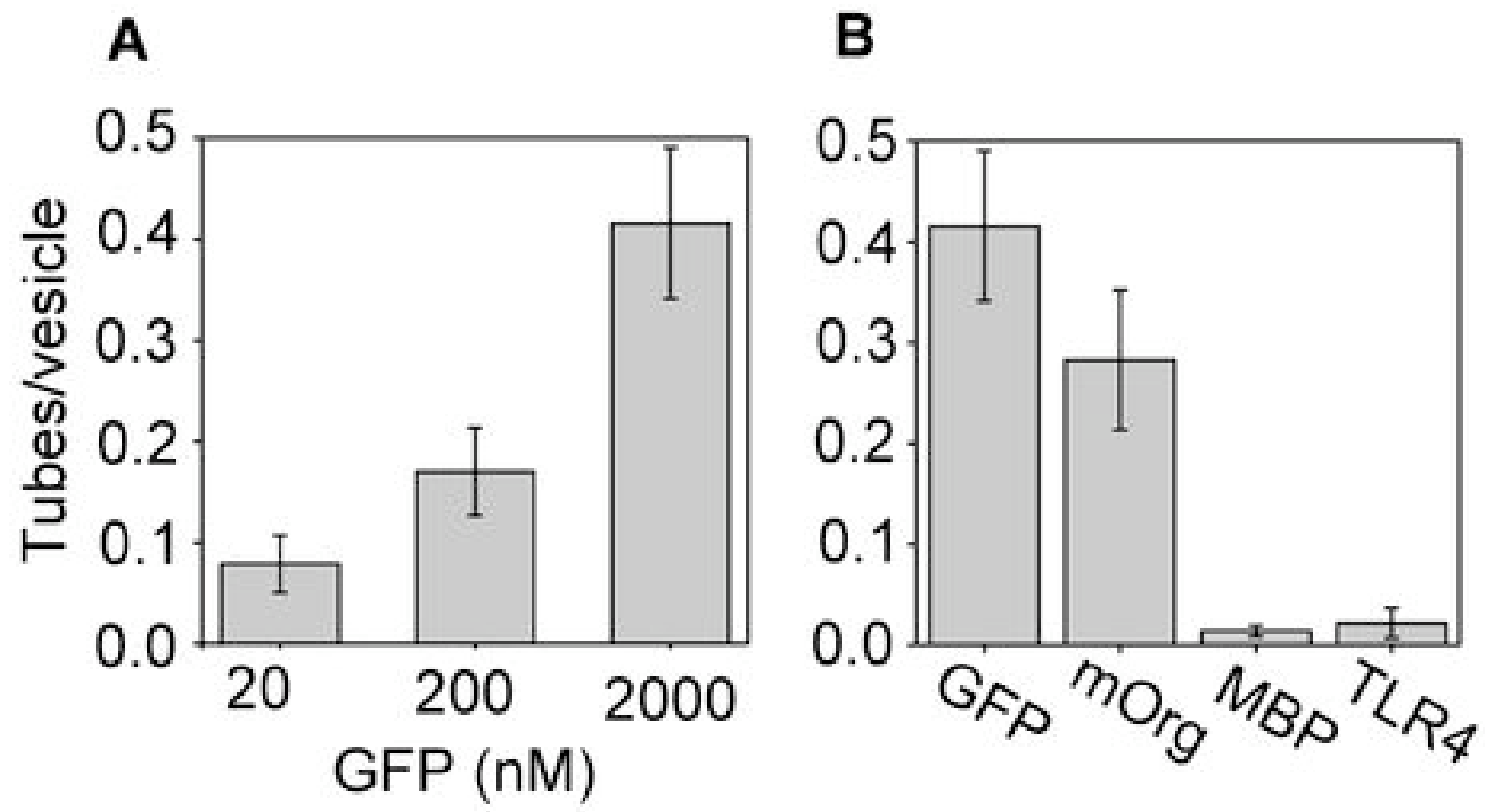

Figure 9. Tubule formation increases with increasing protein concentration and decreases with increasing protein molecular weight, all vesicles 10\% DSIDA / 90\% DPhPC. (A) Frequency of tubule formation as a function of protein concentration (his-GFP, $2 \mu \mathrm{M}$ ). (B) Frequency of tubule formation by various his-tagged proteins having different molecular weights (his-GFP-26 kDa, his-mOrange-26 kDa, his-MBP-66kDa, his-TLR4MD2-125kDa, all $2 \mu \mathrm{M}$ ).

In Figure 9B, we examine the frequency of tubule formation using four different his-tagged proteins of various molecular weight: his-GFP $(26 \mathrm{kDa})$, his-mOrange (26 kDa), his-MBP (66 $\mathrm{kDa})$, and his-TLR4MD2 ( 125 kDa). We observed that lower molecular weight proteins, which will have smaller hydrodynamic radii, to a first approximation, produced membrane tubules with significantly higher frequency. GFP and mOrange have the same molecular weight. However, GFP is known to form trans-dimers, while mOrange has been engineered to prevent dimerization. ${ }^{54}$ The capacity of GFP to form dimers could increase the amount of protein attached to the domain surface, encouraging crowding and tubule formation. However, the high frequency of tubule formation using mOrange indicates that dimerization is not required for tubule formation. Binding of either TLR4MD2 of MBP protein led to formation of well-defined tubules, though the frequency of tubule formation was much lower in comparison to GFP and mOrange. None of these proteins is known to participate in membrane bending processes in vivo. Therefore, the tube formation we observe is likely the result of a general physical 
mechanism that does not require that attached proteins have a specific protein domain or conformation.

\subsubsection{Lipid tubule length is proportional to vesicle diameter}

Since lipid tubules form from domains on the surfaces of vesicles containing a known molar fraction of DSIDA, lipid tubule dimensions (length, diameter) should be related to vesicle dimensions and composition (diameter, domain area). From confocal image scans of the vesicles, we measured the lengths of individual lipid tubules and the diameters of the vesicles they were connected to for varying DSIDA content $(7.5,10,15 \mathrm{~mol} \%)$ upon exposure to $2 \mu \mathrm{M}$ his-GFP. These measurements led to a notable observation - the ratio of the lipid tubule length to the vesicle radius was approximately constant (Fig. 10). Vesicles of increasing DSIDA fraction formed tubules of increasing length relative to vesicle diameter.

Since the domain areas were often fully consumed by tubule formation, it was possible to estimate the radius of lipid tubules, $R_{T}$, from estimates of tubule length, $L_{T}$, vesicle radius, $R$, and domain area fraction, $A_{D}$, by assuming that the domain area is approximately conserved. The average area of DSIDA-rich domains as a percentage of total vesicle surface area was estimated from confocal image stacks (Fig. 10C). Because the fractional domain area and the ratio of tubule length to vesicle diameter are both constant for a given vesicle composition, conservation of domain area implies that tubule diameter is directly proportional to vesicle diameter, suggesting that tubule formation is tightly coupled to vesicle extent (eqn. 1).

A
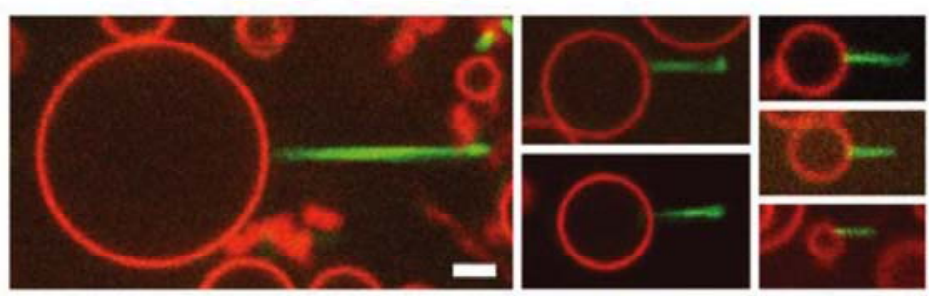

B

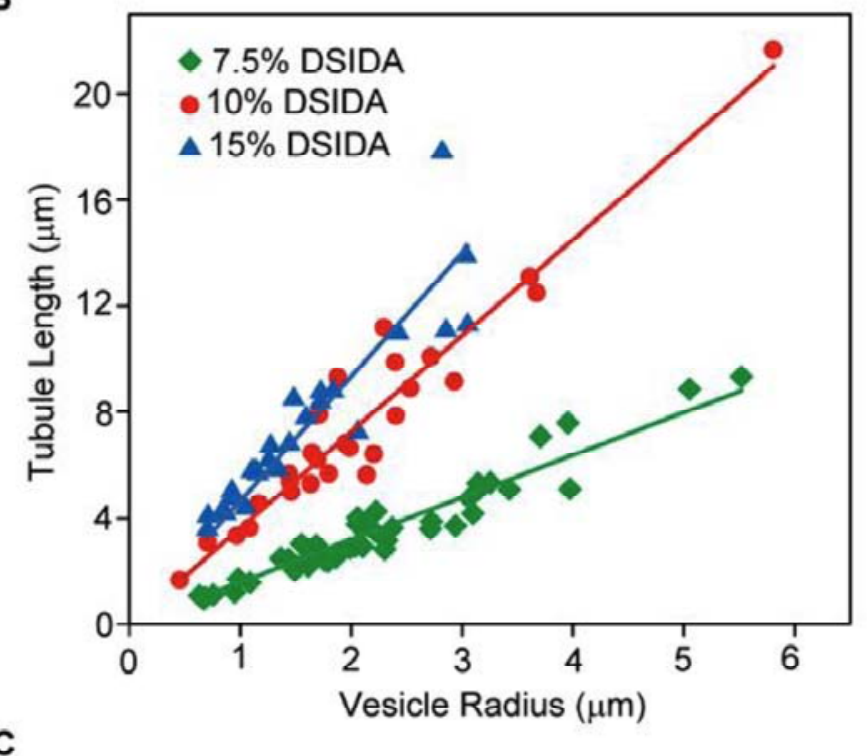

\begin{tabular}{|c|c|c|c|}
\hline DSIDA & AD & RT/R & LT/R \\
\hline $7.5 \%$ & $4.6+/-2.7 \%$ & $0.058+/-0.001$ & $0.80+/-0.016$ \\
\hline $10 \%$ & $5.6+/-1.2 \%$ & $0.031+/-0.001$ & $1.81+/-0.046$ \\
\hline $15 \%$ & $11.4+/-4.4 \%$ & $0.050+/-0.002$ & $2.33+/-0.081$ \\
\hline
\end{tabular}

Figure 10. (A) Lipid tubules formed from GUVs (7.5\% DSIDA / DPhPC / 0.3\% BODIPY). Scale bar, $2 \mu \mathrm{m}$. (B) Tubule length as a function of vesicle diameter $(7.5 \%, 10 \%$, and $15 \%$ DSIDA). (C) Fractional domain surface area, calculated ratio of tubule radius to vesicle radius, and measured ratio of tubule length to vesicle radius. All vesicles exposed to $2 \mu \mathrm{M}$ his-GFP.

$$
\frac{R_{T}}{R}=2 A_{D} \frac{R}{L_{T}}
$$




\subsection{Discussion}

We have shown that protein binding to spatially confined regions of a lipid membrane leads to membrane deformation and tubule formation. Further, the diameter and length of lipid tubules is tightly coupled to size and composition of originating vesicles, suggesting that global parameters may play an important role as tubules form. Here we examine a possible physical basis for tubule formation and discuss the implications of confined protein binding and associated coupling between tubule and vesicle dimensions.

\subsubsection{Lipid tubule geometry may be controlled by a global tension limit}

Previous studies on the formation of lipid tubules in vitro have primarily focused on mechanical pulling of tubules either by direct application of force or the action of motor proteins. ${ }^{55}$ In those experiments tubule radius, $R_{T}$, was found to depend upon the local membrane bending energy, $\kappa$, and initial membrane tension, $\sigma$, according to the expression, $R_{T}=$ $(2 \kappa / \sigma)^{1 / 2} \cdot{ }^{56}$ In contrast we form tubules by a self-assembly process in which proteins crowd onto lipid domains resulting in bending. Protein binding is restricted to domains of fixed area such that tubule surface area is fixed. We observe that the lengths and diameters of lipid tubules increase proportionally with the vesicle diameter, suggesting that global parameters such as the total volume, area, and membrane tension could govern the tubule geometry. In particular, our observations raise two questions: (i) why is the tubule radius to vesicle radius ratio constant for a given composition and (ii) what limits this ratio?

We propose a simple physical analysis based on the principles that protein binding drives membrane deformation, and membrane deformations must conserve membrane area, domain area, and vesicle volume. Briefly, protein binding deforms lipid vesicles, raising membrane tension. The energy required to raise the tension balances against the energy available from protein binding to the domain, defining a maximum membrane tension $\left(\sigma_{\max }\right)$ that depends on fractional domain area $\left(A_{D}\right)$, protein-lipid binding energy $(\Delta G)$, and protein binding density $\left(A_{P}^{-1}\right)$, eqn. 2 .

$$
\left.\sigma_{\max } \approx \frac{3 \Delta G A_{D}}{A_{P}} \approx E \frac{\delta A}{A_{V}}\right|_{\sigma}
$$

Since these parameters do not vary with vesicle diameter, this analysis proposes that the maximum membrane tension is constant with vesicle diameter. Constant membrane tension implies constant membrane area dilation $\left.\left(\delta A / A_{V}\right)\right|_{\sigma}$ across all vesicle diameters, since the area dilation modulus $(E)$ is an intensive property of the membrane. Conserving membrane area and vesicle volume, a constant area dilation requires that the ratio of tubule length and diameter to vesicle diameter be constant for all vesicle diameters. This aspect ratio is limited by the total protein binding energy, a function of fractional domain area, binding constant, and binding density. These predictions are in agreement with our observation of constant tubule aspect ratio and may explain why proteins of smaller molecular weight, which likely increase binding density, form tubules more frequently.

\subsubsection{Biophysical implications of steric confinement and global coupling}

We have shown that lateral crowding of bound proteins on the surface of a lipid microdomain causes spontaneous bending of the domain into a stable lipid tubule of well-defined length (Fig. 11A). We first showed that lipid tubules were not observed when protein binding 
lipids were evenly distributed over GUV surfaces indicating that concentration of protein binding sites, achieved by domain formation, is required for membrane bending. Interestingly, lipid tubule formation from domains was aided by the presence of negative spontaneous curvature lipids, which may partially destabilize the domains, potentially lowering their bending energy, and aid in the formation of the tubules by partitioning to the negative curvature regions at the neck and within the tubule.

Several his-tagged proteins were attached to membrane domains in order to form tubules, none of which has been implicated in membrane bending processes in vivo, suggesting that the mechanism by which tubules are formed does not require a specific protein morphology. The lengths of lipid tubules were observed to vary proportionally with the vesicle diameter, which, according to our analysis, suggests that the system is governed by a global tension limit arising from a balance between protein-lipid binding energy and membrane free energy.

In cellular processes, attachment of specific proteins to lipid bilayers is known to participate in curving membranes as a part of endocytic processes. Several proteins associated with endocytosis have been shown to deform small, originally spherical liposomes into tubules in vitro including amphiphysin ${ }^{62}$ and epsin, ${ }^{38}$ which are required for clathrin-mediated endocytosis, and Sar1p, ${ }^{64}$ which participates in COPII transport vesicle formation. Several specific mechanisms by which protein attachment bends membranes have been described ${ }^{33,65}$ including attachment and pushing of the cytoskeleton; insertion of conically-shaped transmembrane proteins; amphipathic helix insertion (Fig. 11B); and assembly of curved protein scaffolds.

Our results demonstrate a universal mechanism by which confining structures such as lipid domains, scaffolds, and protein lattices could collaborate with membrane binding proteins to induce membrane curvature. Whenever proteins bind with high affinity to a small region of the membrane that is defined by a sufficiently rigid barrier, lateral protein crowding could cause deformation. As we have demonstrated, this mechanism is sufficient to cause membrane curvature on its own (Fig. 11C) without the requirement to specifically disrupt and deform the membranes via processes, such as amphipathic helix insertion. However, our proposed mechanism could also collaborate with such mechanisms by concentrating their membrane bending effects in a small region (Fig. 11B) or amplifying bending as the density of protein on the surface becomes sufficiently high (Fig. 11C). The prevalence of confining structures in membrane bending events suggests that this mechanism, protein coat buckling, may play an important role in vivo. 

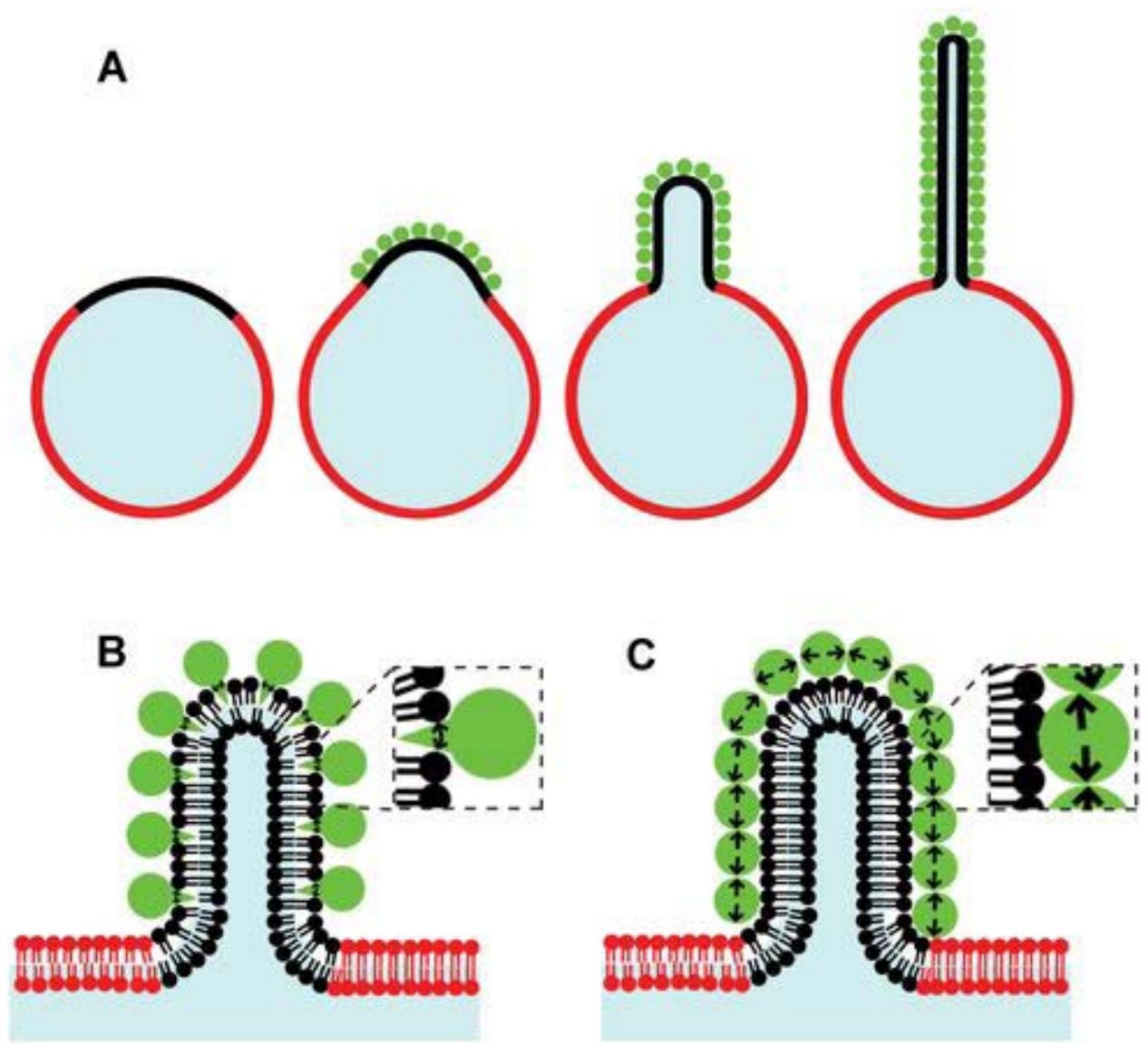

Figure 11. Lipid tubules form when domains crowd protein binding, likely due to a steric crowding mechanism. (A) Schematic showing how domains could crowd protein binding events leading to formation of buds and tubules form domains. (B) Comparison of possible mechanisms of domain bending: amplification of bending by helix insertion (left) and direct protein coat buckling (right). 


\section{CONCLUSIONS}

This report covers only a portion of our work on the project as a number of other important results are currently being put into manuscript form for publication in peer reviewed journals. Of the other results not reported here we have (1) demonstrated the use of motor proteins (kinesin) and cytoskeletal filaments (microtubules) to create lipid nanotubes from giant vesicles that expanded the range of membranes that allowed tubulation to bending rigidities of up to $24 \times 10^{-20} \mathrm{~J}$ (DMPC), (2) shown that we can orient domains and lipid tubules on giant vesicles using electric fields, (3) begun to build systems that capture and probe giant vesicles in a fluidic channel, (4) established cell culture platforms for imaging of cells growing in culture to examine cellular nanotube formation, and (5) designed and synthesized novel lipids and membrane compositions to yield unique membrane structure and properties to tailor domain curvature in giant vesicles. Although we have discovered much about how lipid nanotube formation can be driven by protein affinity and activity we remain curious as to how transport is driven between cells connected by nanotubular networks and how we can exploit those processes to create new nanofluidic systems based on directed assembly. 
[Blank page following section.] 


\section{REFERENCES}

1) Voeltz, G. K.; Rolls, M. M.; Rapoport, T. A. EMBO reports 2002, 3, 944 - 950.

2) Dekker, J. P.; Boekema, E. J. Biochim. Biophys. Acta 2005, 1706, 12 - 39.

3) Rustom, A.; Saffrich, R.; Markovic, I.; Walther, P.; Gerdes, H.-H. Science 2004, 303, 1007 - 1010.

4) Stinchcombe, J. C.; Bossi, G.; Booth, S.; Griffiths, G. M. Immunity 2001, 15, 751 - 761.

5) Önfelt, B.; Nedvetzki, S.; Benninger, R. K. P.; Purbhoo, M. A.; Sowinski, S.; Hume, A. N.; C., S. M.; Neil, M. A. A.; French, P. M. W.; Davis, D. M. J. Immunol. 2006, 177, $8476-8483$.

6) Koyanagi, M.; Brandes, R. P.; Haendeler, J.; Zeiher, A. M.; Dimmeler, S., Circ. Res. 2005, 96, 1039 - 1041.

7) Sherer, N. M.; Lehmann, M. J.; Jimenez-Soto, L. F.; Horensavitz, C.; Pypaert, M.; Mothes, W., Nature Cell Biology 2007, 9(3), 310 - 315.

8) Lee, C.; Ferguson, M.; Chen, L. B., J. Cell Biol. 1989, 109, 2045 - 2055.

9) Peter, B. J.; Kent, H. M.; Mills, I. G.; Vallis, Y.; Butler, P. J. G.; Evans, P. R.; McMahon, H. T., Science 2004, 303, 495 - 499.

10) Shimizu, T.; Masuda, M.; Minamikawa, H., Chem. Rev. 2005, 105, 1401 - 1443.

11) Israelachvili, J. N. Intermolecular and Surface Forces; 2nd ed.; Elsevier Academic Press: San Diego, 1992.

12) McMahon, H. T.; Gallop, J. L. Nature 2005, 438, 590 - 596.

13) Peter, B. J.; Kent, H. M.; Mills, I. G.; Vallis, Y.; Butler, P. J. G.; Evans, P. R.; McMahon, H. T. Science 2004, 303, 495 - 499.

14) Itoh, T.; Erdmann, K. S.; Roux, A.; Habermann, B.; Werner, H.; De Camilli, P. Developmental Cell 2005, 9, $791-804$.

15) Farsad, K.; Ringstad, N.; Takei, K.; Floyd, S. R.; Rose, K.; De Camilli, P. J. Cell Biol. 2001, 155, $193-200$.

16) Chou, T.; Jaric, M. V.; Siggia, E. D. Biophys. J. 1997, 72, 2042 - 2055.

17) Sackmann, E. J. Phys. Condens. Matter 2006, 18, R785 - R825.

18) Walker, S. A.; Kennedy, M. T.; Zasadzinski, J. A., Nature 1997, 387, 61.

19) Horton, M. R.; Manley, S.; Arevalo, S. R.; Lobkovsky, A. E.; Gast, A. P. J. Phys. Chem. B 2007, $111,880-885$.

20) Iglic, A.; Hägerstrand, H.; Bobrowska-Hägerstrand, M.; Arrigler, V.; Kralj-Iglic, V. Phys. Lett. A 2003, 310, 493 - 497.

21) Ratanabanangkoon, P.; Gropper, M.; Merkel, R.; Sackmann, E.; Gast, A. P. Langmuir 2002, 18, 4270 - 4276.

22) Wilson-Kubalek, E. M.; Brown, R. E.; Celia, H.; Milligan, R. A. Proc. Natl. Acad. Sci. USA 
1998, 95, 8040 - 8045 .

23) Dang, T. X.; Farah, S. J.; Gast, A.; Robertson, C.; Carragher, B.; Egelman, E.; Wilson-Kubalek, E. M. J. Struct. Biol. 2005, 150, 90 - 99.

24) Bondurant, B.; Last, J. A.; Waggoner, T. A.; Slade, A.; Sasaki, D. Y. Langmuir 2003, 19, 1829 1837.

25) Yim, H.; Kent, M. S.; Sasaki, D. Y.; Polizzotti, B. D.; Kiick, K. L.; Majewski, J.; Satija, S. Phys. Rev. Lett. 2006, 96, 198101/1 - 198101/4.

26) Hirn, R.; Benz, R.; Bayerl, T. M. Phys. Rev. E 1999, 59, 5987 - 5994.

27) Karlsson, A.; Karlsson, R.; Karlsson, M.; Cans, A.-S.; Strömberg, A.; Ryttsén, F.; Orwar, O. Nature 2001, 409, 150 - 152.

28) Petrov, A. G.; Bivas, I. Prog. Surf. Sci. 1984, 16, 389 - 512.

29) Beblik, G.; Servuss, R. M.; Helfrich, W. J. Phys. (Paris) 1985, 46, (10), 1773 - 1778.

30) Mutz, M.; Helfrich, W. J. Phys. (Paris) 1990, 51, (10), 991 - 1002.

31) Niggemann, G.; Kummrow, M.; Helfrich, W. J. Phys. II France 1995, 5, 413 - 425.

32) Kummrow, M.; Helfrich, W. Phys. Rev. A 1991, 44(12), 8356 - 8360.

33) McMahon HT, Gallop JL (2005) Membrane curvature and mechanisms of dynamic cell membrane remodelling. Nature 438: 590-6.

34) Misra N, et al. (2009) Bioelectronic Silicon Nanowire Devices Using Functional Membrane Proteins. Proc Natl Acad Sci USA 106: 13780-13784.

35) Zhou Y (2008) Lipid Nanotubes:Formation, Templating Nanostructures and Drug Nanocarriers. Crit Rev Sol Sta Mat Sci 33: 183-196.

36) Karlsson M, et al. (2001) Micropipet-Assisted Formation of Microscopic Networks of Unilamellar Lipid Bilayer Nanotubes and Containers. Langmuir 17: 6754-6758.

37) Huttner WB, Zimmerberg J (2001) Implications of lipid microdomains for membrane curvature, budding and fission. Curr Opin Cell Biol 13: 478-84.

38) Ford MG, et al. (2002) Curvature of clathrin-coated pits driven by epsin. Nature 419: 361-6.

39) Sargiacomo M, et al. (1995) Oligomeric structure of caveolin: implications for caveolae membrane organization. Proc Natl Acad Sci USA 92: 9407-11.

40) Sens P, Turner MS (2004) Theoretical model for the formation of caveolae and similar membrane invaginations. Biophys $J$ 86: 2049-57.

41) Subtil A, et al. (1999) Acute cholesterol depletion inhibits clathrin-coated pit budding. Proc Natl Acad Sci U S A 96: 6775-80.

42) Parton RG, Simons K (2007) The multiple faces of caveolae. Nat Rev Mol Cell Biol 8: 185-94.

43) Thiele C, Hannah MJ, Fahrenholz F, Huttner WB (2000) Cholesterol binds to synaptophysin and is required for biogenesis of synaptic vesicles. Nat Cell Biol 2: 42-9. 
44) Simons K, Ikonen E (1997) Functional rafts in cell membranes. Nature 387: 569-572.

45) Baumgart T, et al. (2007) Large-scale fluid/fluid phase separation of proteins and lipids in giant plasma membrane vesicles. Proc Natl Acad Sci USA 104: 3165-3170.

46) Parthasarathy R, Yu CH, Groves JT (2006) Curvature-modulated phase separation in lipid bilayer membranes. Langmuir 22: 5095-9.

47) Hayden CC, Hwang JS, Abate EA, Kent MS, Sasaki DY (2009) Directed formation of lipid membrane microdomains as high affinity sites for His-tagged proteins. J Am Chem Soc 131: 8728-9.

48) Shnek DR, Pack DW, Sasaki DY, Arnold FH (1994) Specific Protein Attachment to Artificial Membranes via Coordination to Lipid-Bound Copper (II). Langmuir 10: 23822388.

49) Pack DW, Chen GH, Maloney KM, Chen CT, Arnold FH (1997) A metal-chelating lipid for 2D protein crystallization via coordination of surface histidines. J Am Chem Soc 119: 2479-2487.

50) Kummrow M, Helfrich W (1991) Deformation of giant lipid vesicles by electric fields. Phys Rev A 44: 8356-8360.

51) Niggemann G, Kummrow M, Helfrich W (1995) The Bending Rigidity of Phophatidylcholine Bilayers: Dependences on Experimental Method, Sample Cell Sealing and Temperature. J De Physique II 5: 413-425.

52) Rand RP, Fuller NL, Gruner SM, Parsegian VA (1990) Membrane curvature, lipid segregation, and structural transitions for phospholipids under dual-solvent stress. Biochem 29: 76-87.

53) Emoto K, et al. (1996) Redistribution of phosphatidylethanolamine at the cleavage furrow of dividing cells during cytokinesis. Proc Natl Acad Sci U S A 93: 12867-72.

54) Shaner NC, et al. (2004) Improved monomeric red, orange and yellow fluorescent proteins derived from Discosoma sp. red fluorescent protein. Nat Biotechnol 22: 1567-72.

55) Derenyi I, et al. (2007) in Controlled Nanoscale Motion (Springer Berlin, Heidelberg), Vol. 711, pp. 141-159.

56) Derenyi I, Julicher F, Prost J (2002) Formation and interaction of membrane tubes. Phys Rev Lett 88: 238101.

57) Sheetz MP, Singer SJ (1974) Biological membranes as bilayer couples, A molecular mechanism of drug-erythrocyte interactions. Proc Natl Acad Sci USA 71: 4457-4461.

58) Lee C, Lin W, Wang J (2001) All-optical measurements of the bending rigidity of lipidvesicle membranes across structural phase transitions. Phys Rev E 64: 020901.

59) Evans E, Rawicz W (1990) Entropy-driven tension and bending elasticity in condensedfluid membranes. Phys Rev Lett 64: 2094-2097.

60) Mader MA, Vitkova V, Abkarian M, Viallat A, Podgorski T (2006) Dynamics of viscous vesicles in shear flow. Eur Phys J E Soft Matter 19: 389-97. 
61) Evans E, Heinrich V, Ludwig F, Rawicz W (2003) Dynamic Tension Spectroscopy and Strength of Biomembranes. Biophys J 85: 2342-2350.

62) Owicki JC, McConnell HM (1979) Theory of protein-lipid and protein-protein interactions in bilayer membranes. Proc Natl Acad Sci USA 76: 4750-4754.

63) Takei K, Slepnev VI, Haucke V, De Camilli P (1999) Functional partnership between amphiphysin and dynamin in clathrin-mediated endocytosis. Nat Cell Biol 1: 33-9.

64) Lee MC, et al. (2005) Sarlp N-terminal helix initiates membrane curvature and completes the fission of a COPII vesicle. Cell 122: 605-17.

65) Hanzal-Bayer MF, Hancock JF (2007) Lipid rafts and membrane traffic. FEBS Lett 581: 2098-104. 
[Blank page following section.] 


\section{DISTRIBUTION}

$\begin{array}{llll}1 & \text { MS9292 } & \text { Darryl Sasaki } & 8621 \\ 1 & \text { MS9052 } & \text { Carl Hayden } & 8353 \\ 1 & \text { MS9291 } & \text { Jeanne Stachowiak } & 8621 \\ 1 & \text { MS9292 } & \text { Steve Branda } & 8621 \\ 1 & \text { MS1303 } & \text { George Bachand } & 1132 \\ 1 & \text { MS9291 } & \text { Robert Meagher } & 8621 \\ 1 & \text { MS1454 } & \text { Mark Stevens } & 1814 \\ 1 & \text { MS9291 } & \text { David Robinson } & 8651 \\ 1 & \text { MS9161 } & \text { Frank Zendejas } & 8621 \\ 1 & \text { MS9671 } & \text { Anupama Sinha } & 8623 \\ 1 & \text { MS9055 } & \text { Julia Wang } & 8353 \\ & & & \\ 1 & \text { MS0899 } & \text { Technical Library } & 9536 \text { (electronic copy) }\end{array}$

For LDRD reports, add:

1 MS0123 D. Chavez, LDRD Office 1011

For CRADA reports add:

1 MS0115 OFA/NFE Agreements 10112

For Patent Caution reports, add:

1 MS0161 Legal Technology Transfer Center 11500 


\section{Sandia National Laboratories}

